\title{
Effect of cation size of iodide salt in the electrolyte on the performance of dye sensitised solar cells
}

\author{
W.V.T. Madhushani, Y.M.C.D. Jayathilake, K.S. Perera* and K.P. Vidanapathirana \\ Department of Electronics, Faculty of Applied Sciences, Wayamba University of Sri Lanka, Kuliyapitiya.
}

Revised: 03 August 2015; Accepted: 26 August 2015

\begin{abstract}
Gel polymer electrolytes (GPEs) have an upsurge interest among scientists due to their fascinating advantages such as leak proof nature, long term stability and good performance. They have been extensively tested for various devices including rechargeable cells, dye sensitised solar (DSS) cells, electrochromic devices and super capacitors. When GPEs are employed for DSS cells, the salt in the electrolyte has been known to play a major role in governing the cell performance. All DSS cells that use iodide/triiodide redox couple comprise a GPE complexed with an iodide salt. Therefore it has been accepted in principle, that GPE should assist iodide ion conductivity.

In this study, GPEs based on several iodide salts were prepared and their performance in DSS cells were evaluated. As such, three different iodide salts, namely, potassium iodide (KI), zinc iodide $\left(\mathrm{ZnI}_{2}\right)$ and tetrapropylammonium iodide $\left(\mathrm{Pr}_{4} \mathrm{NI}\right)$ were chosen for the study. The selection was mainly based on salts with cations having dissimilar sizes and valencies. Among them, KI based gel polymer electrolyte had the highest conductivity. However, the dye sensitised solar cell based on $\mathrm{Pr}_{4} \mathrm{NI}$ exhibited the highest performance. Gel polymer electrolyte based on $\mathrm{ZnI}_{2}$ had the lowest conductivity and also the lowest performance in DSS cells.
\end{abstract}

Keywords: Cation size, dye sensitised solar cells, efficiency, gel polymer electrolytes, ionic conductivity.

\section{INTRODUCTION}

Due to low fabrication costs and reasonably high efficiencies, dye sensitised solar cells (DSSs) have been identified as a very suitable alternative to conventional p-n junction solar cells (Suthanthiraraj, 2013) and they have achieved high solar to electrical energy conversion efficiencies. However, the use of liquid electrolytes in these cells have limited the practical use of such cells because they pose several adverse effects such as leakage of the electrolyte, toxicity of some solvents and desorption of the sensitising dye. One of the proposed alternative approaches to overcome these drawbacks is the use of gel polymer electrolytes (GPEs) instead of liquid electrolytes (Lang et al., 2008; Ahn et al., 2011). Usually GPEs simultaneously exhibit both the cohesive property of a solid and the diffusive transport property of a liquid. They consist of a liquid electrolyte trapped inside a polymer matrix. To prepare the liquid electrolytes in DSSCs, different salts as well as different solvents have been used (Lan et al., 2006; Voigt \& Wullen, 2012). Due to high ionic conductivity, excellent thermal stability and outstanding long term stability, GPEs have been employed in various applications including rechargeable cells (Aravinda et al., 2009; Pandey et al., 2011), dye sensitised solar cells (Perera et al., 2011; Menaka et al., 2013), electrochromic devices (Wu et al., 2013) and supercapacitors (Pandey et al., 2010; Tripathi et al., 2013). There are several factors that govern the ionic conductivity in GPEs and their performance in devices. Among them are the polymer concentration, type of polymer, salt concentration and the type of salt. As far as DSS cells based on iodide/triiodide redox couple are considered, the iodide salt used to prepare the gel polymer electrolyte plays a major role in determining their photovoltaic performance.

In order to support the redox reactions, basically a good iodide ion conducting GPE should be present. As such, the cation of the salt is responsible for improving the anion or iodide ion conductivity. Several groups 
have investigated the effect of the cation on DSS cell performance (Shen et al., 2008; Bhattacharya et al., 2009). The role played by the cations on DSS cell efficiency is two-fold. Firstly is by influencing the short circuit current through iodide ion conductivity and secondly, by affecting the charge injection mechanism at the electrolyte/semiconductor interface. Therefore in summary, it can be stated that the cation size should be large enough to enhance the iodide ion conductivity while having a high charge density to support good photogeneration of electrons at the dye and faster diffusion at the dye-semiconductor interface.

In this study three different iodide salts, namely, potassium iodide (KI), zinc iodide $\left(\mathrm{ZnI}_{2}\right)$ and tetrapropylammonium iodide $\left(\mathrm{Pr}_{4} \mathrm{NI}\right)$ were studied and their ionic conductivity as well as the performance in DSS cells have been investigated. Polyvinylidenefluoride (PVdF) has been used as the polymer, and ethylene carbonate (EC) and propylene carbonate (PC) have been used as the solvents in the GPEs.

\section{METHODS AND MATERIALS}

\section{Preparation of gel polymer electrolytes}

Polyvinylidenefluoride (PVdF - Aldrich), ethylene carbonate (EC - Aldrich), propylene carbonate (PC Aldrich), tetrpropylammonium iodide ( $\left.\mathrm{Pr}_{4} \mathrm{NI}-\mathrm{ABCR}\right)$, zinc iodide $\left(\mathrm{ZnI}_{2}-\right.$ Aldrich $)$ and potassium iodide (KI-Aldrich) with purity greater than $98 \%$ were used without further purification. The composition of gel polymer electrolytes were based on the values reported by Arof et al. (2014). After weighing and magnetically stirring the appropriate amounts of the materials, heating was done at $120{ }^{\circ} \mathrm{C}$ for $15 \mathrm{~min}$. A weight of one tenth of the total mole amount of the iodide salt of iodine $\left(\mathrm{I}_{2}-\right.$ Breckland Scientific Supplies) was later added to the mixture and the final product was hot pressed between two well cleaned glass plates. After leaving inside a dessicator for $24 \mathrm{hrs}$, it was possible to obtain thin electrolyte films with no pinholes and bubbles.

\section{Measurement of ionic conductivity}

A circular shaped pellet was cut from the electrolyte film and loaded inside a brass sample holder with stainless electrodes. The brass sample holder was sealed by means of an $\mathrm{O}$ ring. The diameter and thickness of the pellets were measured by a micrometer screw guage. Impedance data were collected using a Metrohm frequency response analyser (FRA M101) in the frequency range from
$0.01-37 \mathrm{kHz}$. The data were analysed using the Non Linear Least Square (NLLS) fitting method. The intercept on the real axis at high frequency region was taken as the bulk electrolyte resistance of the GPE $\left(R_{b}\right)$. After determining $\mathrm{R}_{\mathrm{b}}$, the ionic conductivity of the sample $(\sigma)$ was calculated using the equation,

$\sigma=\left(1 / \mathrm{R}_{\mathrm{b}}\right)(\mathrm{t} / \mathrm{A})$

where $\mathrm{t}$ is the thickness and $\mathrm{A}$ is the area of cross section of the pellet sample.

\section{Preparation of photo anode}

Fluorine doped tin oxide (FTO) glass slides were cleaned well using detergents and distilled water. The preparation of titanium dioxide $\left(\mathrm{TiO}_{2}\right)$ paste was done by grinding $\mathrm{TiO}_{2}$ alone (Degussa P-25) initially for a few minutes. Then, a few drops of acetic acid and ethanol and one drop of TritonX were mixed. This was spread on an active area of $1 \mathrm{~cm}^{2}$ on FTO glass strips using doctor blade method. Sintering was done at $450{ }^{\circ} \mathrm{C}$ for 45 mins. The resulting nano porous electrodes were allowed to cool down to room temperature and dipped in ethanolic Ruthenium dye (N719) solution for dye absorption for $24 \mathrm{hrs}$.

\section{Fabrication of DSS cells}

A platinum coated glass strip was used as the cathode and three DSS cells were fabricated in the configuration, FTO/TiO $/$ /Dye/Gel polymer electrolyte/Pt/FTO. The photo current - voltage characteristics of the cells were measured under $100 \mathrm{~W}$ illumination.

\section{RESULTS}

One impedance data plot is shown in Figure 1 as a representative example. Z' and Z" stand for real part and imaginary part of the impedance, respectively. The conductivity variation with inverse temperature for all the samples investigated are shown in Figure 2. Table 1 summarises the performance characteristics of solar cells fabricated using the three systems.

\section{DISCUSSION}

Impedance plots taken for gel polymer electrolytes with blocking electrodes normally consist of two semi circles and a spike, at high frequency, intermediate frequency and low frequency, respectively. The semicircle at high frequency region corresponds to bulk electrolyte and the semicircle at intermediate frequency stands for the charge transfer resistance. The low frequency region has 
a spike to represent capacitive features. One impedance plot obtained from the impedance data analysis is shown in Figure 1. It consists of a part of a semicircle in the intermediate frequency region. In all resulted impedance plots, the semicircle at high frequency region was not observed. This is evidently due to the absence of the required frequency range in the measuring system.

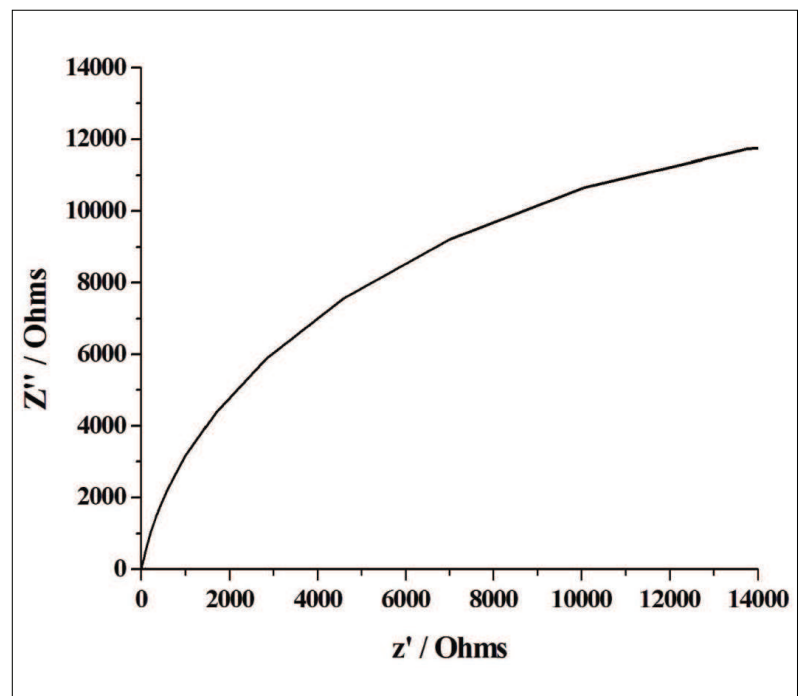

Figure 1: A typical impedance plot obtained for one GPE at room temperature. Intercept on the $\mathrm{X}$ axis was obtained by extrapolating the semicircle

From Figure 2, it is clear that the conductivity of all the samples increase with temperature as expected. Due to the increase of temperature, ions get more kinetic energy and become more mobile resulting a high ionic conductivity. From the three systems GPE based on KI exhibits the highest conductivity, while the GPE based on $\mathrm{ZnI}_{2}$ shows the lowest conductivity at all temperature values. This shows the presence of more $\mathrm{K}^{+}$and $\mathrm{I}^{-}$ions in the KI system than $\mathrm{Zn}^{+}$and $\mathrm{I}^{-}$ions in $\mathrm{ZnI}_{2}$ system. The possible reason may be the higher dissociation energy needed by $\mathrm{ZnI}{ }_{2}$ to form $\mathrm{Zn}^{+}$and $\mathrm{I}^{-}$due to the multivalency. Higher mobility of small, single valent $\mathrm{K}^{+}$ions, compared to the larger, double valent $\mathrm{Zn}^{++}$ions is another reason for the observed higher conductivity of the $\mathrm{KI}$ based electrolyte. As far as $\mathrm{Pr}_{4} \mathrm{Ni}$ is considered, it has a lower conductivity than KI but a higher conductivity than $\mathrm{ZnI}$. In the former, the size of the cation is larger than $\mathrm{K}^{+}$and $\mathrm{Zn}^{+}$. Therefore, its mobility is expected to be lower (Arof et al., 2014). This may be the reason for having a lower conductivity than the KI system. However, due to the presence of the monovalent bulky cation $\mathrm{Pr}_{4} \mathrm{~N}^{+}$, the ionic dissociation and formation of $\operatorname{Pr}_{4} \mathrm{~N}^{+}$and I- ions should be more favourable than in $\mathrm{ZnI}_{2}$. Therefore, $\mathrm{Pr}_{4} \mathrm{NI}$ system poses a higher conductivity than $\mathrm{ZnI}_{2}$.

Solar cell performances shown in Table 1 clearly show that the open circuit potential $\left(\mathrm{V}_{\text {oc }}\right)$ and the short circuit current density $\left(\mathrm{J}_{\mathrm{sc}}\right)$ values are higher for the DSS cells having electrolytes with bulky $\operatorname{Pr}_{4} \mathrm{~N}^{+}$cations.

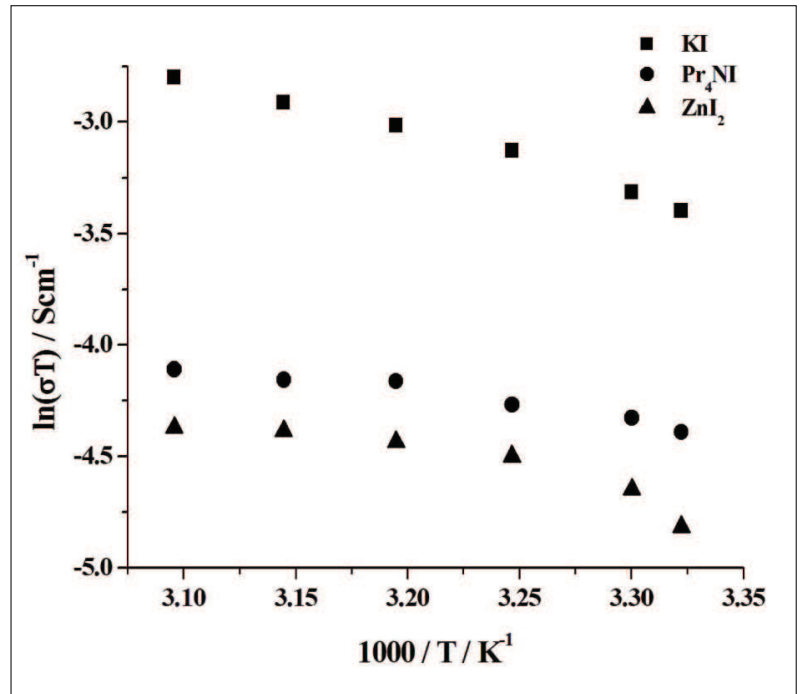

Figure 2: Dependence of conductivity on inverse temperature for GPEs based on salts $\mathrm{Pr}_{4} \mathrm{NI}, \mathrm{KI}$ and $\mathrm{ZnI}_{2}$

Table 1: Characteristics of the solar cells fabricated using three different GPEs

\begin{tabular}{lccc}
\hline & KI system & $\mathrm{Pr}_{4}$ NI system & $\mathrm{ZnI}_{2}$ system \\
\hline $\mathrm{V}_{\text {oc }}(\mathrm{mV})$ & 661.2 & 693 & 593.8 \\
$\mathrm{~J}_{\text {sc }}(\mathrm{mA})$ & 2.08 & 3.1 & 1.68 \\
$\mathrm{FF} \%$ & 47.37 & 45.87 & 49.04 \\
Efficiency, $\eta \%$ & 0.20 & 0.31 & 0.15 \\
\hline
\end{tabular}

In these iodide/triidiode redox couple based DSS cells, charge recombination takes place between the electrons ejected to $\mathrm{TiO}_{2}$ and triiodide in the gel polymer electrolyte. When the size of the cation in the iodide salt is large, triiodide diffusion reduces and this results in reducing the charge recombination. As a result, the Fermi level of $\mathrm{TiO}_{2}$ increases. This increases $\mathrm{V}_{\text {oc }}$ substantially. This is the reason for $\mathrm{V}_{\mathrm{oc}}$ to increase, when the cation size increases.

$\mathrm{J}_{\mathrm{sc}}$ depends on the mobility of iodide ions ( $\left.\mathrm{I}^{-}\right)$, which becomes higher with the size of the cation (Arof et al., 2014). This is expected as the bulky $\operatorname{Pr}_{4} \mathrm{~N}^{+}$cation favours a higher degree of ionic dissociation, thereby increasing the 
number of iodide $\left(\mathrm{I}^{-}\right)$ions needed for the redox reactions. This is the reason for better solar cell performance despite lower conductivity values of the $\mathrm{Pr}_{4} \mathrm{~N}^{+}$based GPE. Higher conductivity of the KI based system comes largely from the higher mobility of $\mathrm{K}^{+}$ions, which does not contribute to solar cell performance. Accordingly, the DSS cell based on $\operatorname{Pr}_{4} \mathrm{NI}$ can show a higher $\mathrm{J}_{\mathrm{sc}}$ than the other two cells. However, this pattern was not followed for KI and $\mathrm{ZnI}_{2}$ systems. Although $\mathrm{K}^{+}$is smaller than $\mathrm{Zn}^{+}, \mathrm{KI}$ based solar cells have higher $\mathrm{V}_{\mathrm{oc}}$ and $\mathrm{J}_{\mathrm{sc}}$. This elucidates the fact that there should be another factor governing the performance other than the size of the cation. $\mathrm{K}^{+}$ and $\mathrm{Zn}^{+}$ions differ in their valency. $\mathrm{K}^{+}$is a mono valent ion while $\mathrm{Zn}^{2+}$ is divalent. Therefore, it can be assumed that due to the multivalent nature, $\mathrm{ZnI}_{2}$ based solar cell showed lower $\mathrm{V}_{\mathrm{oc}}$ and $\mathrm{J}_{\mathrm{sc}}$ in addition to having the lowest ionic conductivity. Fill factors of the three cells are more or less the same as observed by Shen et al. (2008). The efficiencies are very low in all three cells, which may be due to many reasons such as not fine tuning the composition of the gel polymer electrolytes and insufficient amount of iodide introduced. However, from these values it is clear that salts with larger cations generally give rise to higher efficiencies for solar cells. For mono valent cations considered in this study, it is observed that the conductivity variation is related to cell parameters in an opposite way (Bhattacharya et al., 2009).

\section{CONCLUSION}

Larger cations such as $\mathrm{Pr}_{4} \mathrm{~N}^{+}$play a great role in improving the cell performance than high charge density cations such as $\mathrm{K}^{+}$.

\section{Acknowledgement}

Assistance given by the National Research Council (Grant No. 12-109) and the Wayamba University of Sri Lanka (SRHDC/RP /04/13/01) for this project is highly acknowledged.

\section{REFERENCES}

1. Ahn S.H., Kim H.W., Lee S.H., Chi W.S., Choi J.R., Shul Y.G. \& Kim J.H. (2011). Effect of oligomer on dyesensitized solar cells employing polymer electrolytes. Korean Journal of Chemical Engineering 28: 138. DOI: http://dx.doi.org/10.1007/s11814-010-0321-5

2. Aravinda V., Karthikaselvi G., Vickraman P. \& Naganandhini S.P. (2009). Polyvinylidene fluoride-based novel polymer electrolytes for magnesium-rechargeable batteries with $\mathrm{Mg}\left(\mathrm{CF}_{3} \mathrm{SO}_{3}\right)_{2}$. Journal of Applied Polymer
Science 112: 3024 - 3029.

DOI: http://dx.doi.org/10.1002/app.29877

3. Arof A.K., Aziz M.F., Noor M.M., Careem M.A., Bandara L.R.A.K., Thotawathage C.A., Rupasinghe W.N.S. \& Dissanayake M.A.K.L. (2014). Efficiency enhancement by mixed cation effect in dye sensitized soalr cells with a PVdF based gel polymer electrolyte. International Journal of Hydrogen Energy 39: 2929 - 2935.

4. Bhattacharya B., Lee J.Y., Geng J., Jung H.T. \& Park J.K. (2009). Effect of cation size on solid polymer electrolyte based DSS cells. Langmuir 25: 3276 - 3281.

DOI: http://dx.doi.org/10.1021/la8029177

5. Lan Z., Wu J., Wang D., Hao S., Lin J. \& Huang Y. (2006). Quasi solid state dye sensitized solar cells based on gel polymer electrolytes with poly(acrylonitrile-co styrene) / NaI $+\mathrm{I}_{2}$. Solar Energy 80: 1483 - 1488.

DOI: http://dx.doi.org/10.1016/j.solener.2005.11.007

6. Lang L.Y., Jen S.Y. \& Min Y.Y. (2008). A hybrid PVDFHFP/nanoparticle gel electrolyte for dye-sensitized solar cell applications. Nanotechnology 19: 455201 - 455206. DOI: http://dx.doi.org/10.1088/0957-4484/19/45/455201

7. Menaka C., Velu K.S., Manisankar P. \& Stalin T. (2013). Conductivity, structural and electrochemical behavior of plasticized polymer electrolytes for dye sensitized solar cells. Indian Journal of Chemistry 52A: 467 - 472.

8. Pandey G.P., Agrawal R.C. \& Hashmi S.A. (2011). Magnesium ion conducting gel polymer electrolytes dispersed with silica for rechargeable magnesium battery applications. Journal of Solid State Electrochemistry 15: $2253-2264$.

DOI: http://dx.doi.org/10.1007/s10008-010-1240-4

9. Pandey G.P., Hashmi S.A. \& Kumar Y. (2010). Performance studies of activated charcoal based electrical double layer capacitors with ionic liquid groups. Energy and Fuels 24: $6644-6652$.

DOI: http://dx.doi.org/10.1021/ef1010447

10. Perera H.A.C.S., Perera K., Vidanapathirana K., Senevirathne V.A., Rupasinghe W.N.S., Thotawaththage C.A., Senadeera G.K.R. \& Dissanayake M.A.K.L. (2011). Quasi solid state dye sensitized soalr cells with poly(vinylidene-fluoride based gel polymer electrolyte and nano porous $\mathrm{TiO}_{2}$ electrode. In: Solar energy materials, solar cells and solar energy applications, Proceedings of the International Conference on Solar Energy Materials, Solar cells and Solar Energy applications (eds. M.A.K.L. Dissanayake, I.M. Dharmadasa, R. Weerasooriya, G.K.R. Senadeera \& J.M.S. Bandara), Institute of Fundamental Studies, Kandy, Sri Lanka, 28 - 30 July, pp. 186 - 192.

11. Shen X., Xu W., Xu J., Liang G., Yang H. \& Yao M. (2008). Quasi solid state dye sensitized solar cells based on gel electrolytes containing different alkali metal iodide salts. Solid State Ionics 179: 2027 - 2030.

DOI: http://dx.doi.org/10.1016/j.ssi.2008.06.027 
12. Suthanthiraraj S.A. (2013). Application aspects of polymer electrolytes in solar cells. Indian Journal of Pure and Applied Physics 51: 310 - 314 .

13. Tripathi S.K., Jain A., Gupta A. \& Kumari M. (2013). Studies on redox supercapacitor using electrochemically synthesized polypyrrole as electrode material using blend polymer gel electrolyte. Indian Journal of Pure and Applied Physics 51: 315 - 319 .
14. Voigt N. \& Wullen L.V. (2012). The mechanism of ionic transport in PAN based solid polymer electrolytes. Solid State Ionics 208: 8 - 16.

DOI: http://dx.doi.org/10.1016/j.ssi.2011.11.031

15. Wu T.Y., Li W.B., Kuo C.W., Chou C.F., Liu J.W., Chen H.R. \& Tseng C.G. (2013). Study of PMMA based gel polymer electrolyte for electrochromic device. International Journal Electrochem Science 8: 10720 - 10732. 